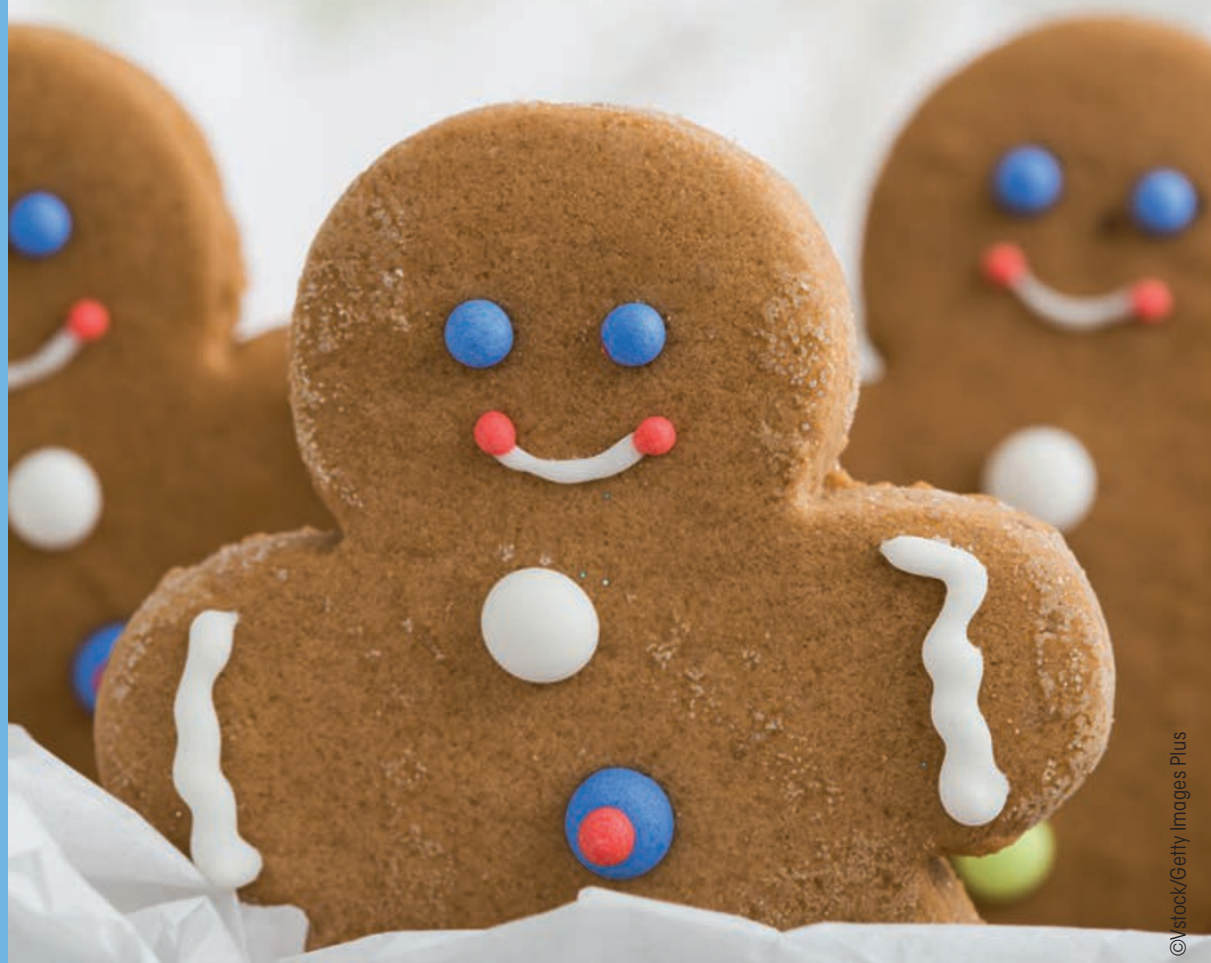

\section{BSDHT SUPPORT CALL FOR FOOD MANUFACTURERS TO CUT SUGAR CONTENT}

The British Society of Dental Hygiene and Therapy (BSDHT) have given their full support to Action on Sugar following their call on 26 October for UK food manufacturers to cut the amount of sugar in their products with immediate effect.

Following new research which shows significant differences in levels of sugar in similar everyday food products, Action on Sugar has urged food manufacturers to fall in line with Public Health England's voluntary reformulation programme to help tackle the health crisis caused by unnecessarily high levels of sugar in our food and drink. ${ }^{1}$

Action on Sugar has discovered that some companies put far less sugar in their products compared to other similar products on the market and believe that the Government's reformulation target of a $20 \%$ reduction in sugar can be easily achieved well before 2020 if companies make changes as a result.

The research looked at foods commonly consumed by children including: breakfast cereals, yoghurts, biscuits, cakes, confectionery, pastries, ice creams and chocolate spreads. They found that that product comparisons with less sugar already exist on the market, for example: ASDA Smart Price Vanilla Flavour Ice Cream (7.9 g) contains $46 \%$ less sugars compared to Waitrose Duchy Organic Vanilla Ice Cream (14.5 g sugars per 100 g) and Organix Goodies Gingerbread Men
Biscuits (18.8 g) contains 38\% less sugars versus McVitie's Mini Gingerbread Men

(30.4 g sugars per $100 \mathrm{~g}$ ) - demonstrating that reducing sugar is possible for manufacturers.

Speaking on the announcement, Michaela ONeill, President of the BSDHT, said: 'It is absolutely heart breaking to see that more than 33,000 children were admitted to hospital last year to have their rotten teeth removed under general anaesthetic.

'By coming in line with Public Health England's voluntary reformation programme food manufacturers have a vital opportunity to do something to help reduce this figure?

The BSDHT have recognised that reformulation, whereby the sugar and sweetness in products are gradually reduced, is an important measure to help reduce the impact of tooth decay in the UK by making people more aware of how often they are consuming sugary foods and drinks by drawing attention to which products have sugar in.

\section{Public Health England. PHE-led} programme asks industry to remove $20 \%$ of the sugar from food eaten by most children. 29 September 2016. Available at: https:/www.gov.uk/government/ news/industry-attends-phe-briefing-onreduction-and-reformulation (accessed November 2016).

\section{Do you}

\section{know an}

\section{outstamaling dental}

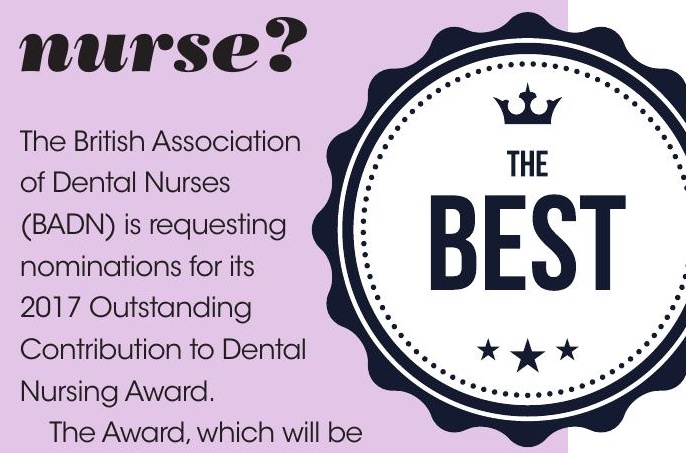

presented in May at the Honours and Awards Dinner at the British Dental Conference and Exhibition, is given to a person deemed by the BADN Executive Committee to have made an outstanding contribution to the development and/or support of the dental nursing profession.

Anyone may nominate - all nominations must be on the official nomination form and all nominations must reach the Chief Executive by midday on 20 January 2017. The person nominated should be a Registered Dental Nurse.

The Award is for an outstanding contribution to the dental nursing profession, which should have had a notable impact nationwide (either UK-wide, or across one of the home countries, eg England, Scotland, Wales, Northern Ireland), have been to the benefit of the dental nursing profession and have been outside the remit of the nominee's paid employment Nominators are asked to write a short narrative on the impact they believe their nominee's contribution has made, showing how their contribution has advanced dental nursing, at what level, who has benefitted in terms of: individuals, including both peers as well as patients; organisations; the profession; or more widely in terms of the whole dental community (nationally and internationally) and how the group(s) have benefitted.

The guidelines for nominating and the nomination form are available at www. badn.org.uk. 